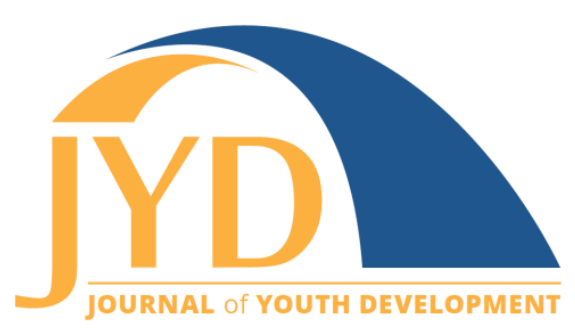

http://jyd.pitt.edu/ | Vol. 16 Issue 4 DOI 10.5195/jyd.2021.1059 | ISSN 2325-4017 (online)

\title{
Framing Indigenous Identity Inclusion in Positive Youth Development: Proclaimed Ignorance, Partial Vacuum, and the Peoplehood Model
}

\author{
Joshua Farella, \\ University of Arizona \\ farella1@email.arizona.edu \\ Joshua Moore \\ University of Arizona \\ jdmoore@arizona.edu \\ Juan Arias \\ University of Arizona \\ juanarias@email.arizona.edu \\ Jeremy Elliott-Engel \\ University of Arizona \\ elliottengelj@email.arizona.edu
}

\begin{abstract}
Indigenous youth are systemically underserved by 4-H and other positive youth development (PYD) organizations. Many underserved First Nation communities in the United States could greatly benefit from programs that foster youth thriving; however, these programs tend to be ineffective in creating culturally reflective spaces for Indigenous participants. In this article, we argue that the Peoplehood Model should serve as a unifying model for the inclusion of Indigenous identity in programming, and that cultural humility should be firmly integrated into program design and assessment. We also propose that, to support Indigenous youth thriving, PYD practitioners must intentionally create a "partial vacuum" that supports youth creating program context and thriving.
\end{abstract}

Key words: Indigenous thriving, identity inclusion, positive youth development, $4-\mathrm{H}$, youth development programming

(cc) EY New articles in this journal are licensed under a Creative Commons Attribution 4.0 License. This journal is published by the University Library System, University of Pittsburgh and is cosponsored by the University of Pittsburgh Press. The Journal of Youth Development is the official peer-reviewed publication of the National Association of Extension 4-H Youth Development Professionals and the National AfterSchool Association. 


\section{Introduction}

4- $\mathrm{H}$ is the largest youth development organization in the United States (R. Lerner \& Lerner, 2013). Indigenous youth are systemically underserved by 4-H (Farella, Hauser, et al., 2021) as well as other youth-serving organizations. 4-H program leaders and Extension directors have noted a systemic lack of service for Indigenous communities (Elliott-Engel, 2018; Hiller, 2005). This is especially concerning since many First Nations in the United States could benefit greatly from programming that fosters youth thriving. In this paper we explore three main ideas relating to youth development within Indigenous communities: (a) recognition of a persistent legacy of exclusion and lack of cultural relevance within educational institutions, (b) identification of themes of identity that can be generalizable or largely relatable in positive youth development (PYD), and (c) exploration of the Peoplehood Model as a suitable framework to inform broad and cohesive social movement(s) supporting Indigenous youth through PYD.

Fields (2020) argued 4-H programming should intentionally ensure access, equity, and belonging to youth representing diverse cultural identities. PYD programming cannot begin without a safe environment, defined as one that provides safety for an individual's physical body, emotional health, and identity (Arnold, 2018; Fields, 2020). Yet, the broad diversity of Indigenous values, beliefs, languages, and places are not systematically represented in PYD research and practice. By recognizing essential elements of identity, practitioners can better design, adapt, evaluate, and critique PYD efforts towards an inclusive space for Indigenous youth.

We propose that the Peoplehood Model (Holm et al., 2003) should be applied as a unifying model of identity inclusion in PYD. The framework explores concrete and philosophical elements that are essential to cultural identity. The Peoplehood Model can be utilized to adapt and frame youth programming in a manner that promotes and strengthens unique Indigenous identities. To accomplish this, youth development efforts must have two main programmatic components: cultural humility and co-creation.

First, practitioners from various backgrounds must cultivate a firm ethic of cultural humility and proclaimed ignorance. In practice, cultural humility is an overt and stated cultural ignorance and a willingness and desire to be taught. Foranda et al. (2016) defined cultural humility as an ethic of "openness, self-awareness, egoless, supportive interactions, and self-reflection and critique" (p. 210; see also Danso, 2018; Van Tongeren, 2019). Open humility and honest ignorance create a setting where one can be instructed. Cultural humility allows practitioners to learn to 
recognize the safe space that youth identify and create. This is complex and evolving-youth can oppose and accept both colonial and traditional elements of identity, and a youth's definition of self is not static. Thus, youth perspective must create the evolving contemporary context (Deyhle, 2014). In the proclamation of immaturity, there is an expectation that individuals will make mistakes. If careful, these "immature" mistakes have the potential to cultivate educational moments and partial inclusion, as opposed to alienation and insult.

Next, participants must help create context and format, thereby creating an educational experience that is personally meaningful. PYD initiatives must create what we have termed a partial vacuum, defined as a program space that buffers youth from dominant and directive cultural narratives to support their creation of personally relevant contexts and metrics of success (Deardorff, 2009; Fields, 2020). As Barnhardt and Kawagley (2005) stated, "Indigenous peoples throughout the world have sustained their unique worldviews and associated knowledge systems for millennia, even while undergoing major social upheavals as a result of transformative forces beyond their control" (p.9). They further argue that, while an understanding of Western society may have a practical necessity, it should not come, "at the expense of what they already know and the way they have come to know it" (p. 9). Identity inclusion is not optional in our work. Without a context of safety and belonging, we cannot truly fulfill our mission as educators.

\section{Background}

The authors' primary lens is 4-H programming, which is foundationally guided by PYD philosophy (Arnold, 2018; J. V. Lerner et al., 2009; R. Lerner \& Lerner, 2013). 4-H programs are administered to communities throughout the United States through land-grant institutions, which include land-grant universities (LGU), historically Black colleges and universities (HBCU), and Tribal colleges and universities (TCU), as instituted through the Morrill Acts of 1862, 1890, and 1994, respectively. The Morrill Act of 1862 gave approximately 10,700,000 acres of Indigenous land to fund the establishment of 52 different LGU's (Lee \& Ahtone, 2020). The lands were seized through 160 land cessions as a result of treaty negotiations and theft (Lee \& Ahtone, 2020). Lightly stated, there is an inherent tension in LGUs "serving" Indigenous communities. The establishment of the LGU system is rooted in the disenfranchisement of First Nations' sovereignty. The LGU system and 4-H program can, and must, provide valuable educational opportunities to Indigenous communities. 
The Smith-Lever Act (1914) established a network of Cooperative Extension services in connection with the LGU system. 4-H Clubs, the youth development program of Cooperative Extension, are one method of providing PYD programs, generally through an experiential learning model (Norman \& Jordan, 2016). Contemporary 4-H programming commonly utilizes the Thriving Model (Arnold, 2018) as a theory of changes to understand contributing factors towards beneficial long-term outcomes. The National 4-H Council (n.d.) has created a strategic plan to increase program participant numbers and to mirror the U.S. demographics in membership by 2025.

A major limitation to the National 4-H strategic plan is that contemporary educational systems descend from a legacy of colonialism and systemic assimilation. Educational initiatives that rely on colonial structures inhibit Indigenous inclusion, success, and sovereignty. Such tools of assimilation were consciously developed, instituted, and remain broadly in practice both overtly and covertly (Arminio, 2006; Blaisdell, 2015; Godlewska et al., 2013; Kirkness \& Barnhardt, 2016; Kohli et al., 2017; Rosenberg, 2015). As these efforts were and are systemic and purposeful, so must be their destruction (Fields, 2020). Active steps must be identified and adopted to combat the assimilation, limitation, and exclusion of Indigenous participants in youth development programs.

Our primary concern in this article is that youth development efforts appear to lack a cohesive strategy for combating these artifacts of colonialism. Practitioners need effective mechanisms to include Indigenous identities and cultural knowledge in order to be effective educators. This effort must be systemic and overt, to provide spaces for Indigenous youth to thrive.

\section{Nomenclature}

"American Indian" and "Native American" are common names used to characterize First Nations Indigenous peoples throughout the United States (Yellow Bird, 1999). The U.S. Department of Agriculture (USDA) and other federal agencies use the standardized language "American Indian/Alaska Natives (AI/AN)" (U.S. Department of the Interior, Indian Affairs, n.d.). The 4-H Program Access, Equity and Belonging (AEBC) Program Leaders Working Group (PLWG) AI/AN Champion Group recognizes the following terms to describe the Indigenous Peoples of the United States: Native Americans, American Indians, Indigenous Americans, and Native Alaskans. The working group emphasizes that, whenever possible, specific tribal names should be used (AEBC, 2020). Yellow Bird argues the diversity of culture and history in AI/AN groups is best described through the nomenclatures of "Indigenous Peoples," or "First Nations People." 
The term "First Nations" accurately promotes recognition of inclusiveness, sovereignty, and identity empowerment sought by Indigenous peoples of North America (Yellow Bird, 1999). While all these terms are in general and professional usage, in this paper we use the terms suggested by Yellow Bird (1999) and the PLWG.

\section{The Status Quo}

The dialogue surrounding Indigenous inclusion is not new. It is arguable that these topics have been, effectively, the proverbial dead horse within many fields. And yet, positive outcomes for Indigenous communities largely have not improved. By any common metric-health, education, economic mobility, etc.-Indigenous youth are profoundly underserved in the United States (Emm \& Breazeale, 2008; Hiller, 2005; Kirkness \& Barnhardt, 2016; Peterson et al., 2002; Wyatt et al., 2015). There are 573 federally recognized First Nations populated by over 2.9 million citizens. Approximately $32 \%$ are under 18 years of age (U.S. Census Bureau, 2020). Yet, per capita, Indigenous youth remain underrepresented in 4-H clubs and other youth development programs (Maloney, 2017).

In the authors' home state of Arizona, the 2019-2020 4-H year had 151 youth self-identify as American Indian/Alaskan Native (AI/AN), which is 3.2 percent of 4-H club membership (4HOnline, 2020). In contrast, the 2018-2019 Arizona Department of Education Indian Education Report noted 55,572 Indigenous youth enrolled in the Bureau of Indian Education and Arizona schools from Grades 3-12, which is $5 \%$ of the student body throughout the state (ADE, 2019). The deficiency in serving Indigenous youth is even more evident at the county level. Navajo and Coconino counties, for example, have very large Indigenous populations ( $45.7 \%$ and $27.45 \%$ respectively), and yet per capita service numbers by Arizona Cooperative Extension remain on par with the rest of the state (U.S. Census Bureau, 2020; 4-H Online, 2020). Cooperative Extension efforts specifically designed for serving Indigenous communities also fall short. Hiller (2005) approximated that Tribal colleges and Extension efforts reached less than $10 \%$ of First Nation citizens. This clear deficiency in PYD efficacy cannot remain the status quo for Indigenous youth.

\section{Existing Efforts and Resources}

Several organizations and bodies of work actively support PYD efforts beneficial to First Nations and Indigenous communities. Albeit an incomplete summary, the organizations and efforts noted below provide support and/or knowledge in the following areas: (a) practical educational 
infrastructure, (b) community-based resources/programs, (c) organizational goals and targeted outcomes, (d) promotion or support of First Nations sovereignty, and (e) community and culturally-based revitalization initiatives.

\section{Federally Recognized Tribal Extension Programs}

The USDA's National Institute of Food and Agriculture (NIFA) supports efforts of 1862 and 1890 land grant universities by providing grant funding for federally recognized Tribal Extension programs (FRTEP) in the areas of 4-H and tribal youth development, agriculture and natural resources management, and entrepreneurship and economic development. These programs serve a subset of Indigenous communities by partnering with First Nations governments. Often Tribal Extension agents are the sole practitioners for all Extension programming within their communities. For example, the University of Arizona has agents serving the Navajo Nation (four agents), Hopi Tribe (one agent), San Carlos Apache (one agent), Colorado River Indian Tribes (one agent), and Hualapai/Havasupai Tribes (one agent). These eight individuals serve approximately 204,064 First Nation citizens (U.S. Census Bureau, 2020). FRTEP programming is funded through competitive grants, in sharp contrast to the guaranteed funding allotted to county Extension offices (Hiller, 2005). While a step in the right direction, Federally Recognized Tribal Extension Programs are under-supported. For example, Arizona encompasses the historical territories of at least 22 distinct First Nations and 17 do not have FRTEP support.

\section{4-H Access Equity and Belonging Committee: American Indian/Alaskan Natives Champions Group}

The 4-H PLWG has established an American Indian/Alaskan Native Champions Group that works to expand knowledge and resources for youth development programs within Indigenous communities. Some important initiatives taken on by this group include adapting the Thriving Model for Indigenous audiences and integrating American Indian Studies philosophy (e.g., The Peoplehood Model) into staff and volunteer cultural competency training (AEBC, 2020a; 2020b; Arnold, 2018).

\section{Language Preservation and Revitalization Efforts}

Language loss is widely recognized as a detriment to cultural health. A language serves as an archive for cultural, philosophical, and environmental knowledge, in addition to unique oral traditions and literature (Walsh, 2005). Language shift towards a non-Indigenous vernacular is often the product of an assimilatory ideology on the part of governmental and educational entities (Hinton, 2014; House, 2002; Jegede, 1995). Revitalization and preservation efforts 
recognize that language loss is an essential element of cultural extinction, and an irrecoverable trove of knowledge disappears along with the language (Arviso \& Holm, 2001; Blair et al., 2002; Crawford, 1996; Hinton, 2014; Holm et al. 2003).

Many First Nations have integrated language revitalization into educational efforts, including immersion programs and culturally centered curricula. A few examples include Tséhootsooí Diné Bi'Ólta' (Dine'é/Navajo Nation immersion elementary school), Hopitutuqaiki (culturally centered curriculum and Hopi language immersion), and the Navajo Language Immersion Institute at Diné College. Also, the Tohono O'odham Community College has integrated a "Himdag" component for all programs offered, which requires students to take several classes celebrating Tohono O'odham culture, including language, songs, storytelling, art, values, beliefs, etc. (Himdag at TOCC, n.d.). This is a limited set of examples. Many First Nations and supporting organizations (e.g., Indigenous Language Institute) have similar initiatives.

\section{Cultural Relevance and Institutional Shortcomings}

Vine Deloria (1990) bluntly notes that contemporary Indigenous education "resembles indoctrination more than it does forms of teaching because it insists on implanting a particular body of knowledge and a specific view of the world, which often does not correspond to the lived experiences that Native people have or might be expected to encounter" (p. 16). Singleperspective paradigms are not specific to education, but pervasive throughout many social systems. U.S. American Indian policies in education (Huffman, 2001; Kohli et al., 2017), healthcare, social and behavioral health (Castor et al., 2006; Wyatt, 2015), criminal justice (Flanagan, 2015), and land (Brown-Rice, 2013) have damaged the physical and cultural health of many Indigenous peoples (Schusky, 1975). Various societal issues result from the loss of cultural cohesion and the resulting trauma (Emm \& Breazeale, 2008; Hiller, 2005; Peterson et al., 2002; Wyatt et al., 2015). In one example, Sioux elders spoke of the disappearance of their people, despite an increasing population. The loss of land through U.S. government Indian policy led to a loss of being Sioux (Schusky, 1975; see also Holm et al., 2003; Basso, 1996). Knowledge and behavioral norms are passed through generations of First Nations people in different ways from culture to culture (Barnhardt \& Kawagley, 2005; Demmert, 1999; García et al., 2009; Warner, 2006). When single elements of language, place, history, and ceremony are removed, identity and social norms are also lost (Basso 1996; Hinton, 2014; Holm 2005; Holm et al. 2003; House 2002). 
Unfortunately, themes of assimilation within educational efforts are not limited to individual programs, ideas, or lessons. In certain ways, these ideas exist as essential tenets of education and PYD philosophy. Many scholars have termed science itself as an overt subculture of Western or Euro-American culture, (Aikenhead, 1997, p. 219; see also Dart, 1972; Jegede, 1995). In more accurate terms, scientific thought is a mechanism incorporating and validating new "correct" knowledge and experience. The innate difficulty here is that single-perspective paradigms have great difficulty in reaching outside of established cultural perspectives (Kuhn, 1962; Woolsey Des Jarlais, 2009). Naturally, this is problematic because peoples incorporate and define wisdom and meaning in different ways.

Participation in rigorously systemic paradigms can require assimilation for achievement. Secondary and post-secondary science courses, for example, are often presented in an orthodox manner that emphasizes a single pathway to truth, inherently rejecting alternative lived experiences and learned wisdom. Jegede (1995) notes, "interference of one world view with another in the learning of science is perhaps much the same as the interference of a first language with the learning of a second" (p. 97). Dart (1972) noted similar disparities in the 1960 s and called for culturally relevant methods of education in marginalized communities and developing countries. Such approaches have been slow to appear and lack social cohesion outside of select case studies (Farella, Hauser, et al., 2021).

Established or "correct" paradigms of thought and knowledge are intrinsic to many contemporary educational systems. As a result, there is an innate cultural discontinuity for many Indigenous participants. Semken (2005) writes, "The educators and researchers most directly engaged with the difficulties AI/AN students have in learning science nearly always cite some form of cultural discontinuity as a root cause" (p. 150). Lived experiences of the participants are not included in the assumed "reality" of the world, and educational content conflicts with the experiential knowledge of the student. Semken suggests that "the practices and practitioners of mainstream or 'Western' scientific research and education constitute an identifiable culture that is foreign to, and typically incompatible with, traditional Indigenous norms and ways of knowing" (p. 150; see also Aikenhead, 1997; Jegede, 1995; Nelson-Barber \& Estrin, 1995).

Such cultural breaks can motivate conscious or unconscious resistance to educational structures or content that contrasts to personal or group experience. Huffman (2001) writes, "Predominant pedagogical styles, the curriculum of the school, the behavioral expectations, the personal 
prejudices of school personnel . . . often convey overt and covert messages that devalue the culture, heritage, and identity of minority students" (p. 15). These educational structures can inspire opposition, where "individuals actively resist and reject the implicit and explicit messages attacking their ethnic identity" (Erickson, 1987, as cited in Huffman, 2001, p. 15). The tendency of institutions to retain such assimilatory structures naturally creates an oppositional response in many individuals. Perhaps most insidious is that youth who resist in order to retain their identity, inevitably fail by the educational standards of the institution.

In many educational settings, there is a distinct dichotomy between the "correct" form of knowledge and the lived experience of the participant. Such contrast can be catastrophically damaging to cultural and individual health. Linguists Nora Marks Dauenhauer and Richard Dauenhauer (1998), note that the overt and covert creation of hierarchy and placement of value regarding cultures is broadly established. Educational systems, intentionally or not, have firmly integrated value judgments of cultures. This is often a primary source of identity conflict and can damage the well-being of the participant. The Dauenhauers write, "Certainly in Alaska, and probably throughout the United States and Canada, Native American individuals and communities are plagued and haunted with anxieties, insecurities, and hesitations about the value of their indigenous language and culture" (pp. 62-63).

It is also important to recognize that change is inherent to culture and identity, necessitating an adaptive model for any educational system. Change is human. Our evolution has witnessed many shifts, such as environmental, social, etc. Yet, different human cultures have survived and persisted. Western education tends to emphasize static perspectives of people and concepts (Kawagley \& Barnhardt, 1998; Kuhn, 1962; Woolsey Des Jarlais, 2009). Yet at its core, tradition is a methodology for surviving and interacting with a changing world (Farella, 1990; 1993). "Indigenous" as a lived identity will change over time, as should educational strategies (Weaver, 2001).

\section{The Publication Problem}

In addition to philosophical and institutional limitations, youth development research within Indigenous communities is poorly disseminated within academic circles. For example, a recent systematic review of Extension literature was conducted to examine mentions of "Tribal," "Native," or "Indian" in context with "4-H" or "youth." Five major journals were searched, yielding 13 papers (Farella, Hauser, et al., 2021). The review also assessed the published program results to characterize cultural relevance, such as mentions of "language," "traditional 
calendar," "ancestral," "territory," or "ceremony." Only four peer-reviewed Extension publications discussed elements of Indigenous identity, and only two papers discussed implementing a program (Garbow et al., 2019; Vettern and Flage, 2018). In addition to a general lack of documentation of work in Indigenous communities, Farella, Hauser, et al. (2021) also noted a deficiency of a cohesive framework or philosophical basis within the literature. None of the publications seemed to have a cohesive or broadly recognized intellectual framework or methodology for working within different cultural landscapes. Further, the existence of a broadly recognized measure of efficacy-one that is both culturally adaptive and consistent with Indigenous culture-was not present (Farella, Hauser, et al., 2021).

\section{Cultural Humility Versus Competence}

There have been many recent discussions in PYD around various approaches to culturally relevant education, most notably the functional or "how to" aspect of delivering programming to a culturally distinct audience. Cultural competence, which is often referenced in these dialogues, generally incorporates self-awareness and an understanding of culture's role in behaviors and values (Deardorff, 2009; Spitzberg \& Changnon, 2009). Recognition of cultural distinctions, such as collectivism vs. individualism, gender roles and hierarchies, and belief systems is essential in the non-judgmental application of cultural or cross-cultural competence (Lustic \& Koester, 1993).

Whereas cultural competence is important in educational settings, discussions of cultural humility integrate an overt need for reflection that allows the practitioner to learn and be educated. As we have previously discussed, institutionalized standards of education often integrate colonialized versions of "correct" knowledge. Awareness of alternative perspectives does not necessitate a change in the institutional structure of education. Humility addresses these institutional shortcomings very directly through an ethic of "openness, self-awareness, egoless[ness], supportive interactions, and self-reflection and critique" (Foranda et al., 2016, p. 210; see also Fisher-Borne et al., 2015). Self-reflection and critique, in particular, are quite important in the process of implementing inclusive change (Danso, 2018; Foranda et al., 2016).

Richmond et al. (2018) note that youth development professionals having cultural humility requires that they be "life-long learners of cultural beliefs, values, and assets who, through selfreflection, have constantly evolving cultural knowledge and skills" (p. 504). In practice, humility is a recognition of the professional's ignorance and immaturity of and within a culture (Van Tongeren et al., 2019). Youth development practice must also recognize cultural practice's 
transformative nature, that is "multiplicity and fluidity" (Richmond et al., 2018 p. 504). Competence reflects a strategy of familiarity and non-judgment, but humility provides something foundationally important, namely the opportunity to be educated (Tervalon et al., 1998; Van Tongeren et al. 2019).

\section{A Unifying Framework for PYD: The Peoplehood Model}

Simpkins et al., (2017) note that three main approaches to addressing diversity have generally been used within PYD: universalistic, ethnic-specific, and multicultural (see also Okamato et al., 2012). Universalistic efforts highlight common experience, content, and interests to create group identity. Ethnic-specific approaches focus on adapting programming to a unique culture, thereby requiring a deep cultural and historical knowledge of the community being served. Multiculturalism emphasizes and celebrates diversity, but recognizes that culturally specific approaches are necessary to serve unique groups (Simpkins et al., 2017). Each of these approaches outlines an institutional response, that is "top-down" to community needs. However, the specific mechanisms for achieving identity inclusion in programming are lacking. We argue that the Peoplehood Model (Holm et al., 2003) can serve as a program-planning tool to create contexts capable of inclusivity, whereas a partial vacuum and proclaimed ignorance (discussed later) provide the mechanism for participants to define and create that context in a culturally relevant way.

Holm et al. (2003) present the Peoplehood Model (or Matrix) as a central paradigm for the interdisciplinary field of American Indian Studies (Figure 1). The model is based on earlier work by Thomas (1969) who argued that amorphous terms such as ethnic needed to be disassociated from the concept of people. Ethnic is a term so vast that Thomas found it to be useless in describing the experiences of First Nation peoples (Thomas, 1969). Holm et al.'s (2003) work ultimately synthesized a broadly inclusive means for discussing culture or people. The Peoplehood Model incorporates four key cultural elements that contribute to individual and group identities: language, sacred history, ceremonial cycle, and territory. Each element is interconnected and an essential component of a people. 
Figure 1. The Peoplehood Model

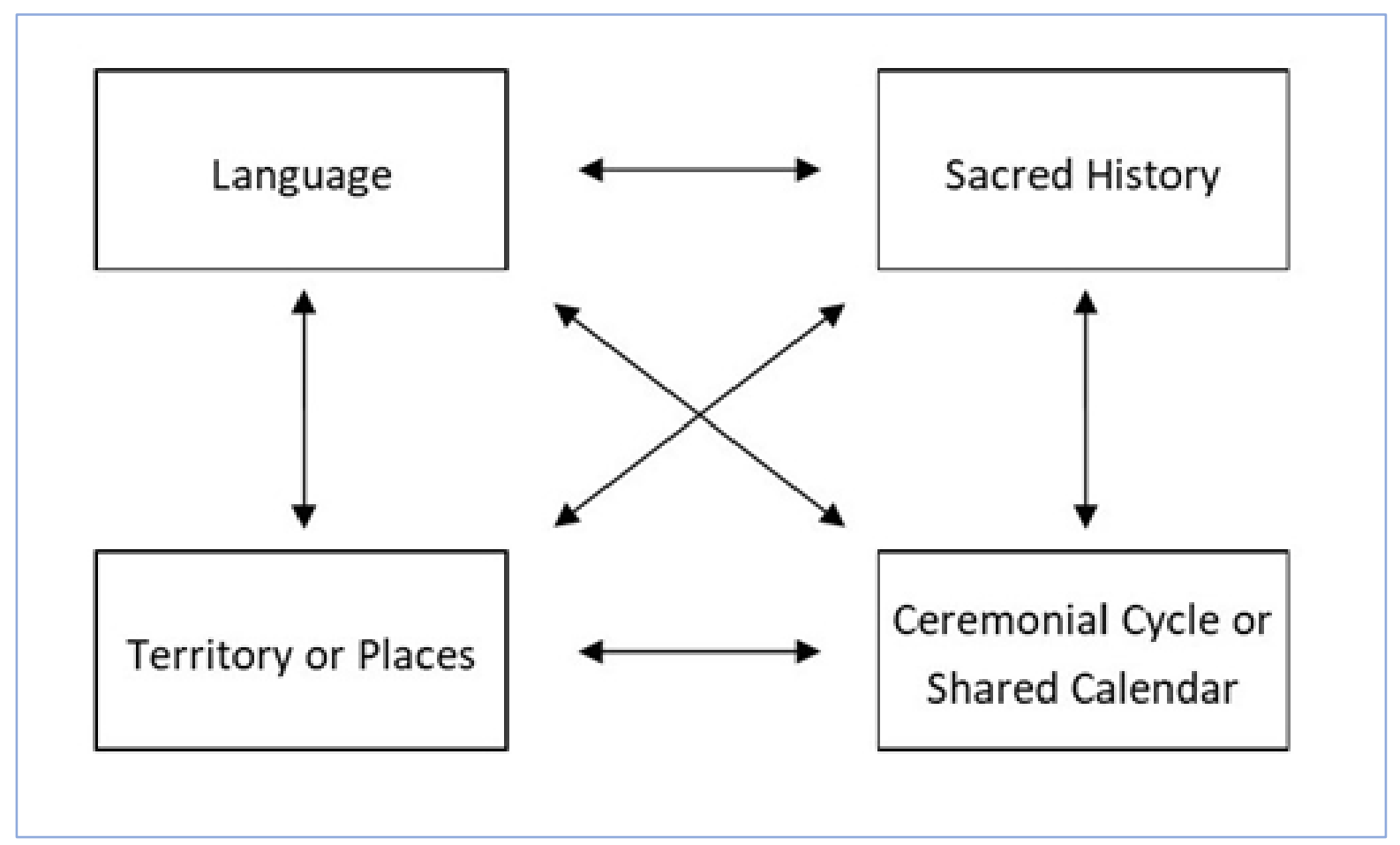

Adapted from Holm et al. (2003).

Perhaps most importantly, Holm et al. (2003) do not define a "persistent people" as a static or discrete entity, but as constantly evolving. The four elements are the negotiation of self and group within a changing environment. This gives each individual an understanding of their past, and also acts as a mechanism to maintain participatory group cohesion. Ultimately, this shared understanding defines not only a social context, but a socio-environmental one: "Sacred history ... details kinship structures, the meaning of ceremonies as well as when they should be performed, and how the group fits within a particular environment" (Holm et al., 2003, p. 14; see also Basso, 1996).

We believe that this model can support Indigenous identity inclusion, cultural relevance, and accessibility in PYD programming. To utilize the Peoplehood Model as an applied framework, careful consideration must be given to how elements of identity should be integrated into educational efforts involving Indigenous youth. 


\section{Creating Program Inclusivity With the Peoplehood Elements}

Holm et al.'s (2003) discussion of the Peoplehood Model originally laid out four elements of a persistent people: language, sacred history, place/territory, and ceremonial cycle. Given the diversity of contexts experienced by contemporary Indigenous youth, we feel that it is necessary to characterize the original language broadly (see Table 1). Our concern is that, in strict interpretation, these terms could be misconstrued as exclusive. For example, if a young person does not speak their ancestral language, it does not exclude them from being part of that "people."

Table 1. Expanded Terminology for Applying the Peoplehood Model Elements in PYD

\begin{tabular}{|l|l|}
\hline Elements of the Peoplehood Model & Examples of expanded terminology in PYD \\
\hline Language & $\begin{array}{l}\text { Indigenous language, parent's/grandparent's/ } \\
\text { guardian's/caregiver's/ elder's/ ancestor's language, } \\
\text { preservation, revitalization }\end{array}$ \\
\hline Territory & $\begin{array}{l}\text { Place(s), traditional place/range, safe space, family space, } \\
\text { personal place(s) }\end{array}$ \\
\hline Sacred history & $\begin{array}{l}\text { History, experience, generational knowledge, ancestral } \\
\text { knowledge }\end{array}$ \\
\hline Ceremonial cycle & $\begin{array}{l}\text { Traditional calendar, cultural calendars, cultural events, } \\
\text { celebrations, festivals, holidays }\end{array}$ \\
\hline
\end{tabular}

Inclusion of these elements into programming and program evaluation can provide a profoundly meaningful experience for youth. Language can foster communication between generations so that cultural memories and stories are told (literally) and understood (metaphorically, symbolically). Also, language is the mechanism for discursive traditions that define a culture's perception of the world. Similarly, places exist, not as static geographic locations, but as reference points for meaning and associations. A sense of place profoundly impacts the way stories, metaphors, and meaning are understood (Basso, 1996). 
Table 2. Positive Outcomes From the Inclusion of the Peoplehood Model Elements

\begin{tabular}{|c|c|}
\hline $\begin{array}{l}\text { Included cultural } \\
\text { element }\end{array}$ & Positive outcomes \\
\hline Language & $\begin{array}{l}\text { - Ownership and pride } \\
\text { - Depth of insight into the cultural experience } \\
\text { - Inter-generational communication-depth of understanding of metaphor, } \\
\text { symbolism, stories, elders } \\
\text { - Recognition of current languages and evolving dialects within Indigenous } \\
\text { communities and youth as a means to include contemporary identity } \\
\text { - Recognition of "contemporary youth" and their adoption of English to } \\
\text { reinvent and reintroduce traditional knowledge (Holm et al. 2003, p. 23) }\end{array}$ \\
\hline Territory/place & $\begin{array}{l}\text { - Shared reference points for stories and cultural experiences } \\
\text { - A sense of place } \\
\text { - Connection to cultural history, stories, and previous generations }\end{array}$ \\
\hline $\begin{array}{l}\text { Cultural experience/ } \\
\text { sacred history }\end{array}$ & $\begin{array}{l}\text { - Framework for cultural memory } \\
\text { - Shared multi-generational experience } \\
\text { - Cultural pride and resilience }\end{array}$ \\
\hline $\begin{array}{l}\text { Ceremonial cycle/ } \\
\text { traditional calendar }\end{array}$ & $\begin{array}{l}\text { - The shared perception of time } \\
\text { - Communal focus on important events-e.g., agricultural harvests, seasonal } \\
\text { migrations, etc. } \\
\text { - A deep and meaningful understanding of community identity, and pride }\end{array}$ \\
\hline
\end{tabular}

Perceiving and marking of time through events and activities is also important. Language, geography, and place are all perceived and described at different scales and moments. Many ceremonial cycles, similar to agrarian calendars, mark seasonal events and inform how cultural wisdom is archived, shared, and discussed (Holm et al., 2003). The marking of time can be spiritual, but also extremely practical. Discrete calendars provide a framework for environmental and philosophical memory. Important elements of identity and livelihood such as cultural origins, social norms, seasonal availability of wild crops, and the planting or harvesting of domestic staples can be documented in a functional way. Stories have no meaning without place, and in turn, places are empty of meaning without human experiences and stories (Basso, 1996). Of course, each of these ideas must exist within a context. History provides an understanding of a culture or youth's place in the world, and how it has changed over time. Understanding both positive and negative relics of history-both past and contemporary-is 
essential in understanding a youth's perspective, and therefore being able to make that youth feel safe.

Each of these elements serves an equally essential part in sustaining cultural identity. In practice, they do not exist in isolation, but as tenets of cultural identity (Hinton, 2014; Stiles, 1997; Walsh, 2005). "Maintaining [Indigenous peoples'] ancestral language [is necessary] because their culture, their ceremonies, and their spiritual history and values can only be transferred through the metaphors inherent in the language and through the cognitive imagery these metaphors invoke" (García et al., 2009, p. 100). Garcia et al. also report numerous anecdotal experiences with contacts from Indigenous communities expressing distress over "the fact that younger tribal members cannot understand important cultural lessons because they speak only English" (2009, p. 100; see also Basso, 1996). In practice, the single loss of language, place, ceremony, or history profoundly inhibits a youth's access and understanding of cultural experience and wisdom.

\section{Discussion}

\section{The Partial Vacuum, Proclaiming Ignorance, and Identity-Based Assessment}

PYD must include a process of discovering new rules of interaction between unique groups and individuals. Such social exploration and negotiation is challenging-all organizations have levels of focus, e.g. policy, administration, risk management. Some of these are essential, for example, background checks are necessary for ensuring the safety of youth. Program design, however, may not require rigidity. Implementation efforts are where shared understanding can happen, and inclusive contexts can be negotiated. 4- $\mathrm{H}$, for example, has pageantry, regalia, symbolism, and ritual, but there are no true absolutes for what each of these elements looks like. Further, 4-H Community Clubs all have unique personalities and cultures-an amalgamation of unique sets of participants and interests. Yet, there must be an overt mechanism for expanding, adapting, and including the existing diversity of our communities as a whole.

To create an identity-inclusive space, a partial vacuum must be provided, i.e., a program space that buffers youth from dominant and directive cultural and integrates the participants' lived experience to define context and metrics of success. In a sense, creating this 'buffer' is a practical application of cultural humility and proclaimed ignorance. By designing program frameworks where participants contribute to the context, the program can become more 
intrinsically meaningful. It is important to remember that single perspective educational efforts have long been employed as a tool of colonial assimilation. Within a partial vacuum, educators can approach participants from the perspective of ignorance. For example, instead of defining a geographic location by name-one most likely found on a colonist's map-educators could ask participants to define places in their terms and integrate their personal experience and characterization into the the program reality. Settings must be created where participants can voluntarily produce the context in which the program occurs, and personal meaning is valued.

Similarly, the metrics of success must be negotiated and adapted to unique individuals and communities of participants. Adapting to such broad cultural diversity and individuality is a difficult task. Yet, setting a single standard of achievement within multiple cultural landscapes echoes the colonist's assimilatory values. The meaning of achievement can profoundly differ from community to community. Whereas practitioners must be cognizant of the societal terms by which individuals "succeed,"-i.e., create a practical livelihood-it must be recognized that success is also profoundly personal. Meeting personal values can take many forms. As an example, consider the positive effects that inspiring pride in an elder can have on youth; no single action across cultures could encourage this response in all caring adults. If youth can, at least partially, determine the terms of their success, then measured achievement can be personally tailored to them.

Assessment and evaluation must overtly involve identity and cultural context. As communities and the cultural competence of the practitioner evolve, so must the tools of reflection. For example, the authors have created a program assessment tool that utilizes the Peoplehood Model to inform culturally relevant evaluation questions (Farella, Moore, \& Arias, 2021). Generally, this tool is a continuation of participants' defining context. To create belonging and a participant-defined context, a program cannot be evaluated from a single perspective of what is "correct." Instead, we propose that the peoplehood elements be utilized as indicators of cultural relevance. A part of the assessment should measure a youth's feeling of cultural belonging within a program. Assessing the cultural relevance of programs allows us to specifically and accurately serve the participant.

\section{Ownership and Privacy}

Cultural knowledge has both public and private aspects. It is easy for professionals to misunderstand in ways that are insulting or, more dangerously, enter a space of meaning that is not meant for them. The importance of privacy and humility cannot be overstated (Foranda 
et al., 2016; Hook et al., 2013). It is profoundly important that those working with Indigenous communities must cultivate a strong ethic of cultural humility, and an overt and proclaimed ignorance (Foranda et al., 2016).

Overstepping boundaries, regardless of their visibility, can earn distrust and alienation. Awareness, humility, and caution must be primary. As an extreme example, we would not suggest those unfamiliar with the customs of First Nation peoples ask about certain elements of Indigenous ceremony. Private cultural knowledge can and should be gained only by invitation. To establish this in practice, youth development professionals must create a context where they have expressed a desire to learn, but also a profound immaturity. With this method, the practitioner establishes a relationship where it is appropriate to be introduced to, and even corrected and taught, proper behaviors within a specific context or social interaction.

\section{Cultural Relevance is Not Optional}

Valuing an individual's identity is essential in youth development (Fields, 2020). Without valuing an individual's cultural identity, programming will lack relevance to the participant and ultimately be ineffective in supporting long-term positive outcomes. Culture is innate to all of us as it guides our perception and experience of the world. We cannot expect single perspectives to truly provide broad inclusivity. Basso (1996) perhaps best describes this essentiality of identity; he proposes that infinite connections exist between thought, place, culture, individuality, and memory. In an individual or group, this can create connectedness, cohesion through these various and sometimes common anchors of social behavior and belonging. A location, for example, exists in different ways to different individuals within a culture. Yet, it can still be essential and important to both the group and the person. Seemingly simple recollections or experiences transcend geography in the literal sense and instead create cultural context. Each location or association inevitably relates to an infinite cultural memory and wisdom, and yet also remain a personal experience (Basso, 1996).

Similarly, each of the Peoplehood Model elements is both distinct and interconnected with the others (Figure 1). Description, perception, and culture are ultimately both defined and created through each of these lenses. Without one element, the others become more difficult, or even impossible, to understand. Take language as an example. García et al. (2009) note in many Indigenous communities there is a belief that "English lacks the descriptive and imagistic characteristics of their Native heritage language- that English is 'dead' in both a spiritual and expressive sense" (p. 100). This is not simply a negative perception of English, but in fact, a 
recognition of potential loss. The authors continue, "Several of our current consultants have commented on the necessity of maintaining their ancestral language because their culture, their ceremonies, and their spiritual history and values can only be transferred through the metaphors inherent in the language and through the cognitive imagery these metaphors invoke," (2009, p. 100). Further, many of the authors' contacts within Native communities were distressed by, "the fact that younger tribal members cannot understand important cultural lessons because they speak only English," (2009, p. 100).

Language, place, history, and ceremony can create profound inclusivity, opportunity, and meaning when integrated with educational efforts. In Alaska, Demmert (1999) created a sustained effort within the primary education system to incorporate Alaskan Native values. Demmert (1999) notes that "Native language, the traditional mores and cultural priorities, the importance of tribal identity and lineage have all become higher priorities." The author cited these efforts as essential in creating a "contemporary culture and context of the school that supports our Native identities" (p. 12). Defining learning from the needs of the participant seems to be an obvious and intuitive approach. Education is a natural extension of identity, a means of transmitting societal norms and expectations. Naturally, if one hails from a perspective outside of those educational norms there is an inherent disconnect. Demmert (1999) concludes that education and academic pursuits cannot be functional in the absence of identity recognition and inclusion, that, "our identity as Indian, an understanding of our past, our role in the modern world, our contributions to society, and service to our communities all affect our academic pursuits as students" (p. 12).

Programs highlighting Indigenous identities have seen success in localized events and case studies (e.g., Charging Home Stampede Fair; Garbow et al., 2019), and there are likely many more successful programs that have not been broadly shared. However, broad synthesis of success within Indigenous communities is not present within our field, and it is sorely needed.

\section{Conclusion}

PYD programming must provide a sense of continuity and familiarity to youth (Arnold, 2018; J. V. Lerner et al., 2013; R. Lerner \& Lerner, 2009). With any group that differs culturally from other groups of participants, programming requires careful consideration. Often the institutional norms reflect a 'majority stakeholder' perspective. A numbers-driven approach is a profoundly 
efficient means of creating an "exclusive" context and revitalizing the colonial elements that many institutions are trying to change.

Participation barriers in experiential and non-formal models of education must be addressed. The method and standardization of organizational goals and outcomes must not emphasize rigor at the cost of cultural relevance. Programs must have real meaning to unique communities. Currently, many institutions offer Indigenous youths the option to participate (and fail to be Indigenous) or participate only partially or not at all (and fail by the institution's metrics). Space must be created for youth to struggle and explore themselves-to define and negotiate their identity. When youth seek to gain cultural knowledge and understand their place within a community, they cannot be judged for what they do not yet know. They too are learning what it means to be Indigenous (Deyhle, 2013). Only by creating a sense of safety and belonging can we support Indigenous youth through this process and enable them to thrive in a personally meaningful way. To fulfill the base tenets of PYD, we must systemically move to reflect, adapt, and build structures in our work that can fulfill these goals.

The Peoplehood Model should serve as a framework for discussing and creating cultural relevance in PYD programs. Programming must be designed and adjusted to promote Indigenous and contemporary youth identities. PYD researchers and practitioners must also incorporate identity-based questions within assessment (e.g., Farella, Moore, \& Arias, 2021) and cultivate a firm ethic of reflection and iterative adaptation by youth development professionals. Although not fully explored in this article, we also see great potential for applying the Peoplehood Model as a means of identity inclusion for all youth. As it is a means of valuing cultural identity, we expect the model could be adapted to better serve a wide diversity of groups and individuals.

The publication problem needs to be corrected. Above all, practitioners must seek to understand and share the nature of successful programming within Indigenous communities. Youth development literature has relatively few publications discussing program work with First Peoples, and a cohesive strategy for implementing and assessing this work is lacking. Part of this is the problematic relationships between tribal communities, human subject researchers, and institutions, such as LGUs. Distrust of researchers and institutions stems from a long legacy of abuse and oppression. But these limitations are not absolute. Youth development work is happening in Native communities. Such stories are the most important element in helping practitioners learn how to be effective and make real positive change in young Indigenous lives. 


\section{Acknowledgement}

Thank you to our supportive colleagues, Gloria Blumanhourst and Trent Teegerstrom. Their careful review was foundational in the publication of this work.

\section{References}

Access, Equity and Belonging Program Leaders Working Group. (2020a). Cultural Competency for 4-H Volunteers. National 4-H Council. https://campus.extension.org/

Access, Equity and Belonging Program Leaders Working Group. (2020b). Reviewing the 4-H Thriving Model with an equity lens [manuscript submitted for review]. National 4-H Council.

Aikenhead, G. (1997). Toward a First Nations cross-cultural science and technology curriculum. Science Education, 81(2), 217-237. https://doi.org/10.1002/(SICI)1098-237X(199704)81:2<217: :AIDSCE6 $>3.0 . C O ; 2-\mathrm{I}$

Arminio, J. L. (2006). [Review of the book Institutional Racism in Higher Education, by I. Law, D. Phillips, \& L. Turney]. Journal of College Student Development, 4オ1), 125-127. https://doi.org/10.1353/csd.2006.0001

Arnold, M. E. (2018). From context to outcomes: A thriving model for 4-H youth development programs. Journal of Human Sciences and Extension, 6(1), 141-160.

Arviso, M., \& Holm, W. (2001). Tséhootsooídi olta'gi Diné bízaad bihoo'aah: A Navajo immersion program at Fort Defiance, Arizona. In L. Hinton, \& K. Hale (Eds.), The green book of language revitalization in practice (pp. 203-215). BRILL. https://doi.org/10.1163/9789004261723 017

Barnhardt, R., \& Kawagley, O. (2005). Indigenous knowledge systems and Alaska Native ways of knowing. Anthropology and Education Quarterly, 36(1), 8-23.

\section{https://doi.org/10.1525/aeq.2005.36.1.008}

Basso, K. H. (1996). Wisdom sits in places. University of New Mexico Press.

Blair, H., Rice, S., Wood, V., \& Janvier, J. (2002). Daghida: Cold Lake First Nation works towards Dene language revitalization. In Indigenous languages across the community. Proceedings of the Annual Conference on Stabilizing Indigenous Languages. pp. 90-98.

Blaisdell, B. (2015). Schools as racial spaces: Understanding and resisting structural racism. International Journal of Qualitative Studies in Education, 29(2), 248-272. https://doi.org/10.1080/09518398.2015.1023228

Brown-Rice, K. (2013). Examining the theory of historical trauma among Native Americans. The Professional Counselor, 3(3), 117-130. http://tpcjournal.nbcc.org 
Castor M.L., Smyser M.S., \& Taualii M. M., (2006). A nationwide population-based study identifying health disparities between American Indians/Alaska Natives and the general populations living in select urban areas. American Journal of Public Health, 96(8) 1478-1484.

Crawford, J. (1996). Seven hypotheses on language loss causes and cures (Publication No. ED395731). ERIC. https://eric.ed.gov/?id=ED395731

Danso, R. (2018). Cultural competence and cultural humility: A critical reflection on key cultural diversity concepts. Journal of Social Work, 18(4), 410-430. https://doi.org/10.1177/1468017316654341

Dart, F. E. (1972). Science and the worldview. Physics Today, 25(6), 48-54.

Deloria Jr., V. (1990). Traditional education in the modern world. Winds of Change, 5(10), 16-18.

Dauenhauer, N. M., \& Dauenhauer, R. (1998). Technical, emotional, and ideological issues in reversing language shift: Examples from Southeast Alaska. In L. A. Grenoble \& L. J. Whaley (Eds.), Endangered languages (pp. 57-98). Cambridge University Press.

\section{https://doi.org/10.1017/cb09781139166959.004}

Deardorff, D. K. (2009). The SAGE Handbook of Intercultural Competence. SAGE Publications.

Demmert, W. G. (1999). Indian education revisited: A personal experience. Journal of American Indian Education, 38(3), 5-13.

Deyhle, D. (2013). Listening to lives: Lessons learned from American Indian youth. In J. Reyhner, J, Martin, L. Lockard \& W.S. Gilbert. (Eds.) Honoring our children: Culturally appropriate approaches for teaching Indigenous students, (pp. 1-10). Northern Arizona University.

Elliott-Engel, J. (2018). State administrators' perceptions of the environmental challenges of cooperative extension and the 4-H program and their resulting adaptive leadership behaviors (Doctoral dissertation). Virginia Tech. https://vtechworks.lib.vt.edu/handle/10919/9800

Emm, S., \& Breazeale, D. (2008). Determining the needs of American Indian audiences for cooperative extension programs. Journal of Extension, 46(1). https://archives.joe.org/joe/2008february/rb1.php

Farella, J. R. (1993). The wind in a jar. University of New Mexico Press.

Farella, J. R. (1990). The main stalk: A synthesis of Navajo philosophy. University of Arizona Press.

Farella, J., Hauser, M., Parrott, A., Moore, J. D., Penrod, M., \& Elliott-Engel, J. (2021). 4-H Youth development programming in Indigenous communities: A critical review of cooperative extension literature. Journal of Extension, 59(3), Article 7. https://doi.org/10.34068/joe.59.03.07

Farella, J., Moore, J., \& Arias, J. (2021). Applying the Peoplehood Model: A model for assessing Indigenous identity inclusion in extension programming (AZ1909-2020). University of Arizona Cooperative Extension. https://extension.arizona.edu/sites/extension.arizona.edu/files/pubs/az1909-2021.pdf 
Fields, N. I. (2020). Literature review: Exploring 4-H thriving through an equity lens. National 4-H Council. https://access-equity-belonging.extension.org/wp-content/uploads/2020/02/LiteratureReview-Thriving-Model-Equity-Lens-FINAL-4.pdf

Flanagan, J. (2015, April 27). Reservation to prison pipeline: Native Americans are the unseen victims of a broken US justice system. Quartz. https://qz.com/392342/native-americans-are-the-unseenvictims-of-a-broken-us-justicesystem

Fisher-Borne, M., Montana Cain, J., \& Martin, S. L. (2015). From mastery to accountability: Cultural humility as an alternative to cultural competence. Social Work Education, 34(2), 165-181. https://doi.org/10.1080/02615479.2014.977244

Foronda, C., Baptiste, D. L., Reinholdt, M. M., \& Ousman, K. (2016). Cultural humility: A concept analysis. Journal of Transcultural Nursing. 27(3), pp. 210-217. https://doi.org/10.1177/1043659615592677 4HOnline. (2020). Enrollment data. Retrieved November 2020 from https://www.4honline.com/ Garbow, J., Jokela, R. H., Rudi, J., \& Serido, J. (2019). Using American Indian legends to teach youths financial literacy: Innovative approaches to cultural adaptation. Journal of Extension, $5 \lambda(1)$. https://archives.joe.org/joe/2019february/pdf/JOE v57 1iw5.pdf

García, J. G., Axelrod, M., \& Lachler, J. (2009). English is the dead language: Native perspectives on bilingualism. In P. V. Kroskrity \& M. C. Fields (Eds.), Native American language ideologies (pp. 99-122). University of Arizona Press.

Godlewska, A. M. C., Schaefli, L. M., \& Chaput, P. J. A. (2013). First Nations assimilation through neoliberal educational reform. Canadian Geographer, 5ス3), 271-279. https://doi.org/10.1111/cag.12016

Hiller, J. G. (2005). Is $10 \%$ good enough? Cooperative extension work in Indian country. Journal of Extension, 43(6), 19-31. https://archives.joe.org/joe/2005december/a2.php

Himdag at TOCC. (n.d.). Retrieved October 2020 from https://tocc.edu/himdag/

Hinton, L. (2014). Language revitalization: An overview. In I. Hinton, \& K. Hale (Eds.), The green book of language revitalization in practice (pp. 203-215). BRILL. https://doi.org/10.1163/9789004261723 017

Holm, T. (2005). The great confusion in Indian Affairs: Native Americans and whites in the progressive era. University of Texas Press. https://doi.org/10.1086/ahr.111.3.846

Holm, T., Pearson, J. D., \& Chavis, B. (2003). Peoplehood: a model for the extension of sovereignty in American Indian studies. Wicazo Sa Review, 18(1), 7-24. https://doi.org/10.1353/wic.2003.0004 Hook, J. N., Davis, D. E., Owen, J., Worthington, E. L., \& Utsey, S. O. (2013). Cultural humility: Measuring openness to culturally diverse clients. Journal of Counseling Psychology, 60(3), 353366. https://doi.org/10.1037/a0032595 
House, D. (2002). Language shift among the Navajos: Identity politics and cultural continuity. University of Arizona Press.

Huffman, T. (2001). Resistance theory and the transculturation hypothesis as explanations of college attrition and persistence among culturally traditional American Indian students. Journal of American Indian Education, 40(3).

Jegede, O. J. (1995). Collateral learning and the eco-cultural paradigm in science and mathematics education in Africa. Studies in Science Education, 25(1), 97-137. https://doi.org/10.1080/03057269508560051

Kawagley, A. O., \& Barnhardt, R. (1998). Education indigenous to place: Western science meets native reality. University of Alaska, Fairbanks.

Kirkness, V., \& Barnhardt, R. (2016). First nations and higher education: The four R's-respect, relevance, reciprocity, responsibility. Journal of College and University Student Housing.

Kohli, R., Pizarro, M., \& Nevárez, A. (2017). The "new racism" of K-12 schools: Centering critical research on racism. Review of Research in Education 41(1). https://doi.org/10.3102/0091732X16686949

Kuhn, T. S. (1962). The structure of scientific revolutions. University of Chicago Press.

Lee, R., \& Ahtone, T. (March 30, 2020). Land-grab universities. High Country News. https://www.hcn.org/issues/52.4/indigenous-affairs-education-land-grab-universities

Lerner, J. V., Phelps, E., Forman, Y. E., \& Bowers, E. P. (2009). Positive youth development. In R. Lerner \& L. Steinberg (Eds.), Handbook of Adolescent Psychology (pp. 524-558). John Wiley \& Sons. https://doi.org/10.1002/9780470479193.adlpsy001016

Lerner, R., \& Lerner, J. (2013). The positive development of youth: Comprehensive findings from the 4-H study of positive youth development. National 4-H Council.

Lustic, M. W., Koester, J. K., (1993). Intercultural competence: Interpersonal communication across cultures. Harper Collins.

Maloney, W. (2017, February 21). Native American FFA members discuss the future of agriculture with USDA officials [Web log post]. Retrieved October 13, 2020, from https://www.usda.gov/media/blog/2013/07/23/native-american-ffa-members-discuss-futureagriculture-usda-officials

Morrill Act of 1862. United States Code, Public Law 37-108, July 2, 1862

National 4-H Council (n.d.). 4-H strategic plan for 2025. https://4-h.org/wp-content/uploads/2016/10/4H-2025-Vision.pdf

Nelson-Barber, S., \& Estrin, E. T. (1995). Bringing Native American perspectives to mathematics and science teaching. Theory Into Practice, 34(3), 174-185.

Norman, M. N., \& Jordan, J. C. (2016). Using an experiential model in 4-H. University of Florida. 
Okamoto, D., Gast, M., Feldman, V. (2012, August). Managing diversity in youth-serving organizations [Paper presentation]. American Sociological Association Annual Meeting, Denver, CO.

Peterson, S., Berkowitz, G., Cart, C. U., \& Brindis, C. (2002). Native American women in alcohol and substance abuse treatment. Journal of Health Care for the Poor and Underserved, 13(3), 360378.

Richmond, A., Braughton, J., \& Borden, L. M. (2018). Training youth program staff on the importance of cultural responsiveness and humility: Current status and future directions in professional development. Children and Youth Services Review, 93, 501-507. https://doi.org/10.1016/j.childyouth.2018.07.022

Rosenberg, G. N. (2015). The 4-H harvest: Sexuality and the state in rural America. University of Pennsylvania Press.

Schusky, E. (1975). The forgotten Sioux: An ethnohistory of the Lower Brule reservation. Taylor Trade Publications.

Semken, S. (2005). Sense of place and place-based introductory geoscience teaching for American Indian and Alaska Native undergraduates. Journal of Geoscience Education, 53(2), 149-157.

Simpkins, S. D., Riggs, N. R., Ngo, B., Vest Ettekal, A., \& Okamoto, D. (2017). Designing culturally responsive organized after-school activities. Journal of Adolescent Research, 32(1), 11-36. https://doi.org/10.1177/0743558416666169

Spitzberg, B. H., \& Changnon, G. (2009). Conceptualizing intercultural competence. In D. K. Deardorff (Ed.), The SAGE Handbook of Intercultural Competence (pp. 2-52). SAGE. https://www.sagepub.com/sites/default/files/upm-binaries/30482 1.pdf

Stiles, D. B. (1997). Four successful Indigenous language programs. In Teaching Indigenous languages (ED415079). ERIC. https://files.eric.ed.gov/fulltext/ED415079.pdf

Tervalon, M., Murray-Garcia, J. (1998). Cultural humility versus cultural competence: A critical distinction in defining physician training outcomes in multicultural education. Journal of Health Care for the Poor and Underserved, 9(2), 117-125.

Thomas, R. K. (1969). Colonialism: Classic and internal. New University Thought, 4(4), 37-44.

U. S. Department of the Interior, Indian Affairs. (2020). Frequently asked questions: Why are American Indians and Alaska Natives also referred to as Native Americans. Retrieved October 15, 2020, from https://www.bia.gov/frequently-asked-questions

U.S. Census Bureau. (2020). Explore Data. Retrieved October 15, 2020, from https://www.census.gov/data.html

Van Tongeren, D. R., Davis, D. E., Hook, J. N., \& Witvliet, C. van O. (2019). Humility. Current Directions in Psychological Science. https://doi.org/10.1177/0963721419850153 
Journal of Youth Development | http://jyd.pitt.edu/ | Vol. 16 Issue 4 DOI 10.5195/jyd.2021.1059

Framing Indigenous Identity Inclusion

Vettern, R., \& Flage, L. (2018). Assessing results of 4-H mentoring with Native American first generation 4-H youths. Journal of Extension, 56(3).

https://archives.joe.org/joe/2018june/pdf/JOE v56 3a8.pdf

Walsh, M. (2005). Will indigenous languages survive? In Annual Review of Anthropology, 34, 293-315. https://doi.org/10.1146/annurev.anthro.34.081804.120629

Warner, L. S. (2006). Native ways of knowing: Let me count the ways. Canadian Journal of Native Education, 29(2), 149-164.

Weaver, H. N. (2001). Indigenous identity: What is it, and who really has it?. American Indian Quarterly, $25(2), 240-255$.

Woolsey Des Jarlais, C. L. (2009). Cultural characteristics of western educational structures and their effects on local ways of knowing [Unpublished doctoral dissertation]. The University of Montana.

Wyatt, L. C., Ung, T., Park, R., Kwon, S. C., \& Trinh-Shevrin, C. (2015). Risk factors of suicide and depression among Asian American, Native Hawaiian, and Pacific Islander youth: A systematic literature review. Journal of Health Care for the Poor and Underserved, 26(2), 191-237. https://doi.org/10.1353/hpu.2015.0059

Yellow Bird, M. (1999). What we want to be called. The American Indian Quarterly, 23(2). https://doi.org/10.2307/1185964 